\title{
Aluminum-induced Neurofilamentous Changes in Cultured Rat Dorsal Root Ganglia Explants
}

\author{
Mark R. Gilbert, ${ }^{1,5}$ Beverly L. Harding, ${ }^{1}$ Paul N. Hoffman, ${ }^{2}$ John W. Griffin,, ${ }^{1,3}$ Donald L. Price, ${ }^{1,4}$ and Juan C. \\ Troncoso ${ }^{1,4}$ \\ Departments of ${ }^{1}$ Neurology, ${ }^{2}$ Ophthalmology, ${ }^{3}$ Neuroscience, and ${ }^{4}$ Pathology, and the ${ }^{5}$ Oncology Center, The Johns \\ Hopkins University School of Medicine, Baltimore, Maryland 21205
}

\begin{abstract}
Intrathecal administration of aluminum (Al) salts to susceptible species causes prominent accumulations of neurofilaments (NFs) in neurons of the CNS. Involved nerve cells display abnormal phosphorylation of perikaryal NFs, impaired axonal transport of NFs, and reduced levels of mRNA for NF proteins. Further understanding of the pathogenesis of Al toxicity has been limited by difficulties inherent in the available in vivo systems. For this reason, we have developed a model to study the effects of Al on cultured sensory neurons.
\end{abstract}

Explant cultures of rat dorsal root ganglia (DRG) were exposed to $1 \mathrm{~mm}$ aluminum lactate for $1 \mathrm{~d}, 3 \mathrm{~d}$, or $7 \mathrm{~d}$ and then examined morphologically. Accumulations of NFs were noted as early as $1 \mathrm{~d}$ after exposure, and prominent masses of NFs were seen at 3 and $7 \mathrm{~d}$. Northern analysis of mRNA extracted from the cultured ganglia showed that high, medium, and low molecular weight NF protein mRNA levels were markedly reduced compared to control values by $1 \mathrm{~d}$ of exposure. Class II $\beta$-tubulin mRNA was also moderately decreased. Reversibility of toxicity was assessed by removing the aluminum lactate from the medium after a $3 \mathrm{~d}$ exposure and examining the cultures 1 week later. The perikaryal masses of NFs dispersed and the levels of mRNA coding for the NF proteins and class II $\beta$-tubulin increased.

The neurotoxic effects of Al on cultured DRG recapitulates the effects of intrathecal administration of Al on animals; this model produces similar changes in neuronal morphology with neurofilamentous masses and similar modifications of NF gene expression. The development of these NF abnormalities in neurons from rat DRG suggests that the apparent selective vulnerability of certain animal species and neurons to Al neurotoxicity is related to the access of the toxin to its target. This culture system will be useful for studying the effects of Al and possibly other toxins in a controlled setting.

The intrathecal administration of aluminum salts into young rabbits causes prominent accumulations of neurofilaments (NFs) (Terry and Pena, 1965; Embree et al., 1967; Wisniewski et al.,

Received Jan. 10, 1991; revised Oct. 29, 1991; accepted Dec. 6, 1991.

We thank Frank Barksdale, Carol Rubright, and Adelaine Stocks for their assistance with the morphologic studies, Marcus Shagogue for the production of the photomicrographs, and Dr. Pamela Talalay for editorial assistance. This work was supported by NIH Grants NO1339 (M.R.G.), NS RO1 17484 (J.W.G.), and NS 25369 and NS 10580 (J.C.T.). A portion of this work was presented at the 1989 American Association of Neuropathology meeting in Dallas, Texas.

Correspondence should be addressed to Dr. Mark Gilbert, Department of Medicine, Montefiore University Hospital, 3459 Fifth Avenue, Pittsburgh, Pᄉ 15213.

Copyright (C) 1992 Society for Neuroscience 0270-6474/92/121763-09\$05.00/0
1967; Exss and Summer, 1973; Selkoe et al., 1979; Troncoso et al., 1982; Bizzi et al., 1984; Cole et al., 1985; Bizzi and Gambetti, 1986; Muma et al., 1988) as well as abnormal phosphorylation (Bizzi and Gambetti, 1986; Troncoso et al., 1986) of NFs in the perikaryon of selected neuronal populations (Wisniewski et al., 1967; Troncoso et al., 1982), associated with a marked decrease in the axonal transport of NFs (Bizzi et al., 1984; Troncoso et al., 1985). In anterior horn cells, levels of mRNAs for all three NF proteins fall markedly, with a moderate reduction in levels of tubulin mRNA, as assessed both by in situ hybridization and Northern analysis (Muma et al., 1988).

Although the molecular pathogenesis of $\mathrm{Al}$ neurotoxicity is not well understood, recent studies have demonstrated that $\mathrm{Al}$ and other multivalent cations can cause aggregation of purified NFs in vitro (Troncoso et al., 1990). This observation suggests that free $\mathrm{Al}$ ions, acting as bridges among charged residues on neighboring filaments, may cause cross-linking and accumulation of NFs in the neuronal perikaryon. Further pathogenetic studies of Al toxicity, however, have been particularly difficult to pursue in animal models because the agent must be introduced intrathecally rather than systemically, only certain neuronal populations have been found susceptible, and only some species, notably rabbits, are affected by the agent. For these reasons, we used an in vitro model, which has inherent advantages in studies of pathogenetic mechanisms. Culture systems allow control over toxin exposure, permit frequent observation and sampling, and provide more uniform populations of cells for study. In this investigation, we asked whether explants of rat dorsal root ganglia (DRG) in vitro might be susceptible to the toxic effects of $\mathrm{Al}$, even though the species and the neuronal population have previously been considered insusceptible to $\mathrm{Al}$.

\section{Materials and Methods}

\section{Establishing the cultures}

Explant cultures of dorsal root ganglia were established as described previously (Wood, 1976). Timed pregnant Sprague-Dawley rats, at 16 d gestation, were deeply anesthetized with methoxyflurane (Metafane, Pittman-Moore, Atlanta, GA), and the uteri were removed under sterile conditions in a laminar flow hood. Individual fetuses were removed from the uterus, and the spinal cord with attached DRG was then extracted using a dissecting microscope. The ganglia were removed at the dorsal roots by using jeweler's forces and placed into a $35 \mathrm{~mm}$ tissue culture dish that had been coated with rat tail collagen. Eight ganglia were placed in each dish containing $1 \mathrm{ml}$ of $\mathrm{N} 2$ (defined medium) composed of Ham's F-12 (50\%, GIBCO, New York, NY), Dulbecco's modified essential medium (50\%, GIBCO), insulin, progesterone, selenium, putrescine, and glucose (Sigma, St. Louis, MO), and supplemented with 7S-NGF (nerve growth factor, Advanced Biotechnologies, Inc., Silver Spring, MD). The culture medium was replenished twice a 


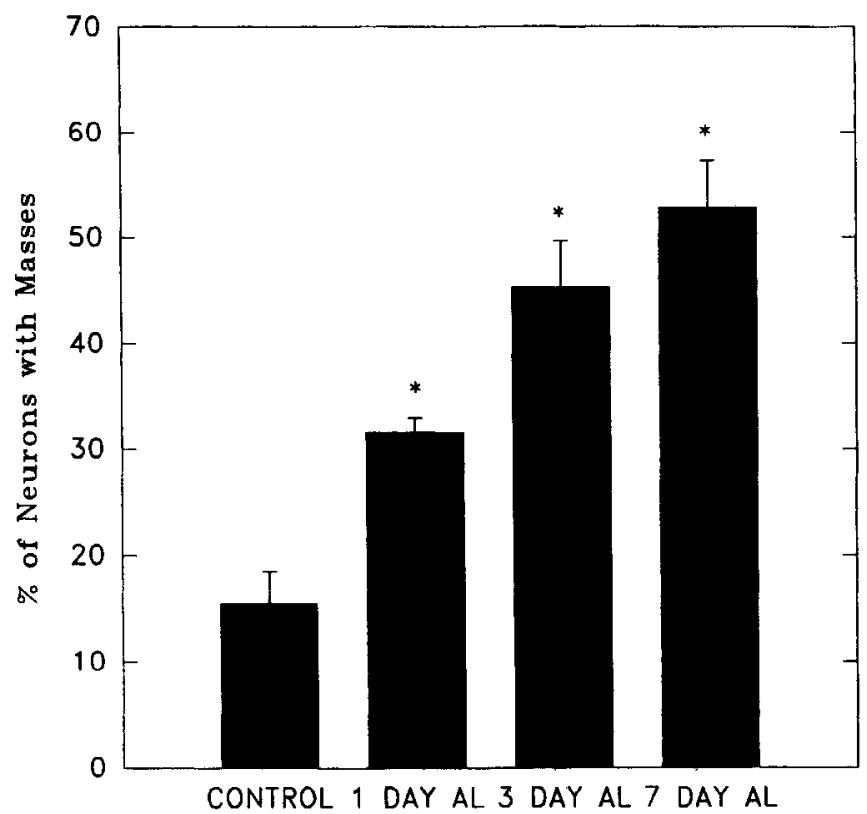

Experimental Groups

Figure 1. Quantitation of argyrophilic perikaryal masses in DRG neurons. The percentage of neuronal nuclei with dark-staining masses was calculated in the aluminum-treated and untreated cultures. The error bars represent the SEM. ${ }^{*}, p<0.01$ compared with control (untreated) cultures.

week. Cultures were maintained in a humidified incubator at $35^{\circ} \mathrm{C}$ containing $8 \% \mathrm{CO}_{2}$.

\section{Experimental design}

Cultures were maintained for 4 weeks in N2 defined medium. At this time, phase-contrast microscopic examination of the cultures showed dense radial outgrowth of neurites from the central ganglia. The average neurite length was $0.5-0.6 \mathrm{~cm}$. The 4 week time point was chosen because previous experiments indicated that there is very little further elongation of neurites after this time on the collagen matrix. Additionally, previous investigations have shown that mRNA levels of low molecular weight NF protein (NF-I), class II $\beta$-tubulin, and GAP-43 changed little with increasing age after 4 weeks in vitro (Gilbert et al., 1989).

The explant cultures received aluminum lactate at a concentration of $1 \mathrm{~mm}$ in the nutrient medium for varied times $(1 \mathrm{~d}, 3 \mathrm{~d}, 7 \mathrm{~d}$ ); at physiologic $\mathrm{pH}$ the concentration of free ionic aluminum has been estimated to be $3 \times 10^{-12} \mathrm{M}$ (Macdonald and Martin, 1988). The start of the exposure was adjusted for each group so that the completion of the exposure time occurred exactly at 5 weeks in vitro. To assess recovery from exposure, cultures were incubated with $1 \mathrm{~mm}$ aluminum lactate in the medium for $3 \mathrm{~d}$, washed, and then maintained in $\mathrm{N} 2$ defined medium for 1 week more. Control cultures continued to receive nutrient medium. At the end of the exposure period, 55-65 ganglia were removed from both experimental and control groups and stored at $-80^{\circ} \mathrm{C}$ for mRNA analysis. The remaining cultures were fixed in either $10 \%$ for- malin or $2 \%$ glutaraldehyde for subsequent histologic or electron microscopic examination.

\section{Histologic techniques}

Light microscopy. Ganglia explants fixed in $10 \%$ formaldehyde were dehydrated through alcohols, embedded in paraffin, and sectioned at 8 $\mu \mathrm{m}$. Sections were stained using the silver method of Bielchowsky.

Electron microscopy. Ganglia explants were fixed in $2 \%$ glutaraldehyde, postfixed with $0.1 \%$ osmium tetroxide, dehydrated, and infiltrated with an Epon/Araldite mixture in the tissue culture dishes. Following polymerization at $60^{\circ} \mathrm{C}$ for a $1 \mathrm{~d}$, the plastic layer containing the cells was separated from the dish, and explants were remounted and reembedded. Sections $(1 \mu \mathrm{m})$ were stained with toluidine blue for light microscopy. Ultrathin sections were cut at $80 \mathrm{~nm}$, stained with uranyl acetate/ lead citrate and examined in a transmission electron microscope at 80 $\mathrm{kV}$.

\section{Measurement of $m R N A$ levels}

The ganglia were homogenized in $4 \mathrm{M}$ guanidine isothiocyanate and purified by centrifugation through a cushion of $5.7 \mathrm{M}$ cesium chloride at $41,000 \mathrm{rpm}$ for $18 \mathrm{hr}$ in a TLS-55 rotor. The RNA was dissolved in diethylpyrocarbonate (DEPC)-treated water at $65^{\circ} \mathrm{C}$, purified by phenol extraction, and concentrated by ethanol precipitation. RNA was redissolved in a final volume of $12 \mu \mathrm{l}$ of DEPC water, and its concentration was determined by measuring optical density at a wavelength of 260 $\mathrm{nm}$. This procedure yielded 10-12 $\mu \mathrm{g}$ of total RNA from the processed 55-65 ganglia. The RNA was analyzed on 1\% agarose gels containing $6.6 \%$ formaldehyde; $5 \mu \mathrm{g}$ of RNA were used on each gel slot. After electrophoresis, the RNA was blotted onto nylon membranes (Gene Screen, Du Pont, Wilmington, DE) and hybridized with ${ }^{32} \mathrm{P}-\mathrm{cDNA}$ probes for 2-3 d. Cloned DNA probe for high molecular weight NF protein (NF-H) was generously provided by Dr. Ivan Lieberberg (Athena Neurosciences, San Francisco, CA); the cDNA probe for medium molecular weight NF protein (NF-M) by Dr. David Nelson (Baylor College of Medicine); the cDNA probe for NF-L, by Dr. Nicholas Cowan (New York University); and the cDNA probe for class II $\beta$-tubulin, by Dr. Stephen Farmer (Boston University). The cDNA probes were labeled with ${ }^{32} \mathrm{P}$ by using Klenow agent in the presence of random primers and labeled dATP. Blots were washed with $0.1 \%$ SDS, $0.1 \times$ saline-sodium citrate $(3 \times 20 \mathrm{~min})$ at $50^{\circ} \mathrm{C}$. The labeled hybrids were detected by autoradiography with $\mathrm{x}$-ray film (Kodak, Rochester, NY). Integrated optical density from the autoradiographies was determined with a computerized image analysis system (Loats, Inc., Westminster, MD).

\section{Results}

Histology

As displayed in Figure 1, examination of histologic sections stained by the Bielchowsky method demonstrated argyrophilic perikaryal masses in $15 \%$ of neuronal cell bodies in untreated cultures. In contrast, in aluminum-treated cultures, up to $50 \%$ of neurons contained argyrophilic masses in the perikaryon. Furthermore, these masses stained more intensely in the aluminum-treated ganglia than in controls.

\section{Electron microscopy}

Electron microscopic examination confirmed a progressive accumulation of NFs in the perikaryon over the course of the $\mathrm{Al}$

Figure 2. Electron micrograph of perikaryal region of cultured DRG neuron after $1 \mathrm{~d}$ of exposure to Al. $A$, Early coalescence of filamentous structures in the left perinuclear region. $B$, Higher magnification of the perinuclear region boxed in $A$, demonstrating disarray of filaments. $C$, Portion of the perinuclear region with NFs the predominant structures present (from boxed region in $B$ ). Scale bars: $A$ and $B, 1 \mu \mathrm{m} ; C, 0.1 \mu \mathrm{m}$.

Figure 3. Electron micrograph of perikaryal region of cultured DRG neuron after $3 \mathrm{~d}$ of exposure to Al. $A$, Marked coalescence of filaments in the perinuclear region. $B$, Higher magnification of the region of the perinuclear mass boxed in $A$, showing almost complete absence of other cytoplasmic elements. $C$, Section of the perinuclear mass showing almost exclusively NFs (from boxed region in $B$ ). Scale bars: $A$ and $B, 1 \mu$ m; $C$, $0.1 \mu \mathrm{m}$.

Figure 4. Electron micrograph of perikaryal region of cultured DRG neuron after $7 \mathrm{~d}$ of exposure to Al. $A$, Dense perinuclear mass with rare cytoplasmic elements. $B$, Disordered filaments in the perinuclear mass (from boxed region in $A$ ). $C$, Section of the perinuclear mass showing almost exclusively NFs (from boxed region in $B$ ). Scale bars: $A$ and $B, 1 \mu \mathrm{m} ; C, 0.1 \mu \mathrm{m}$. 


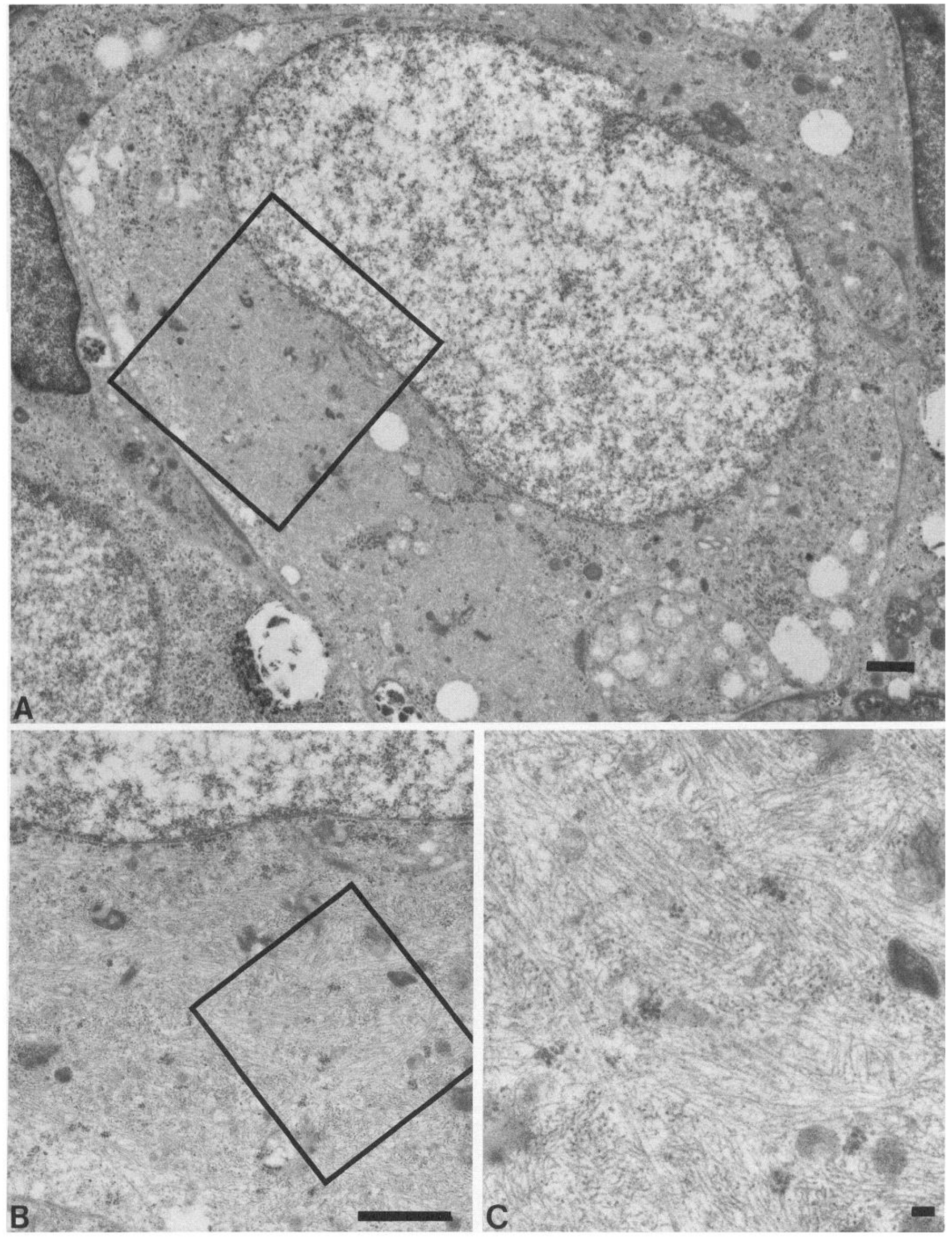




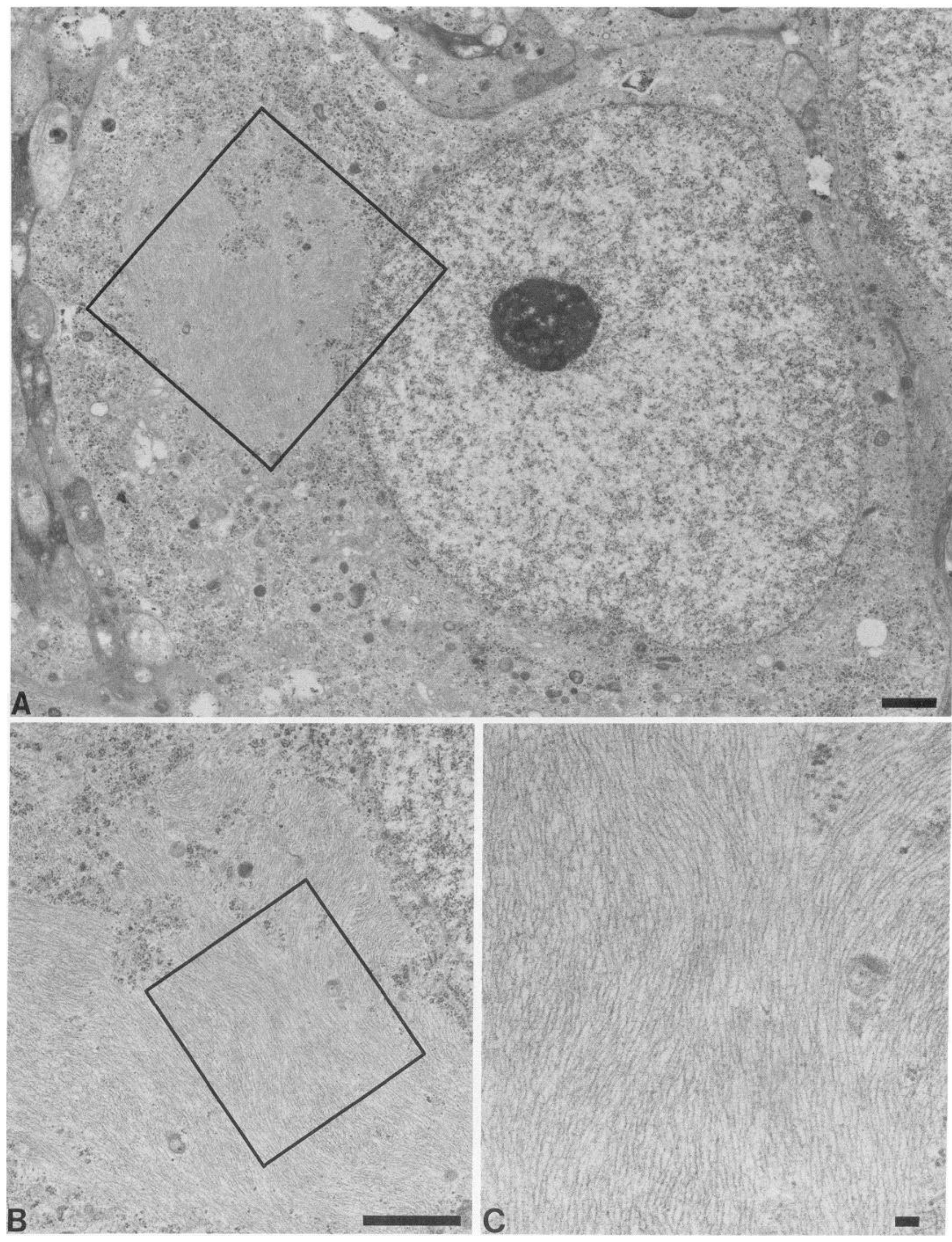




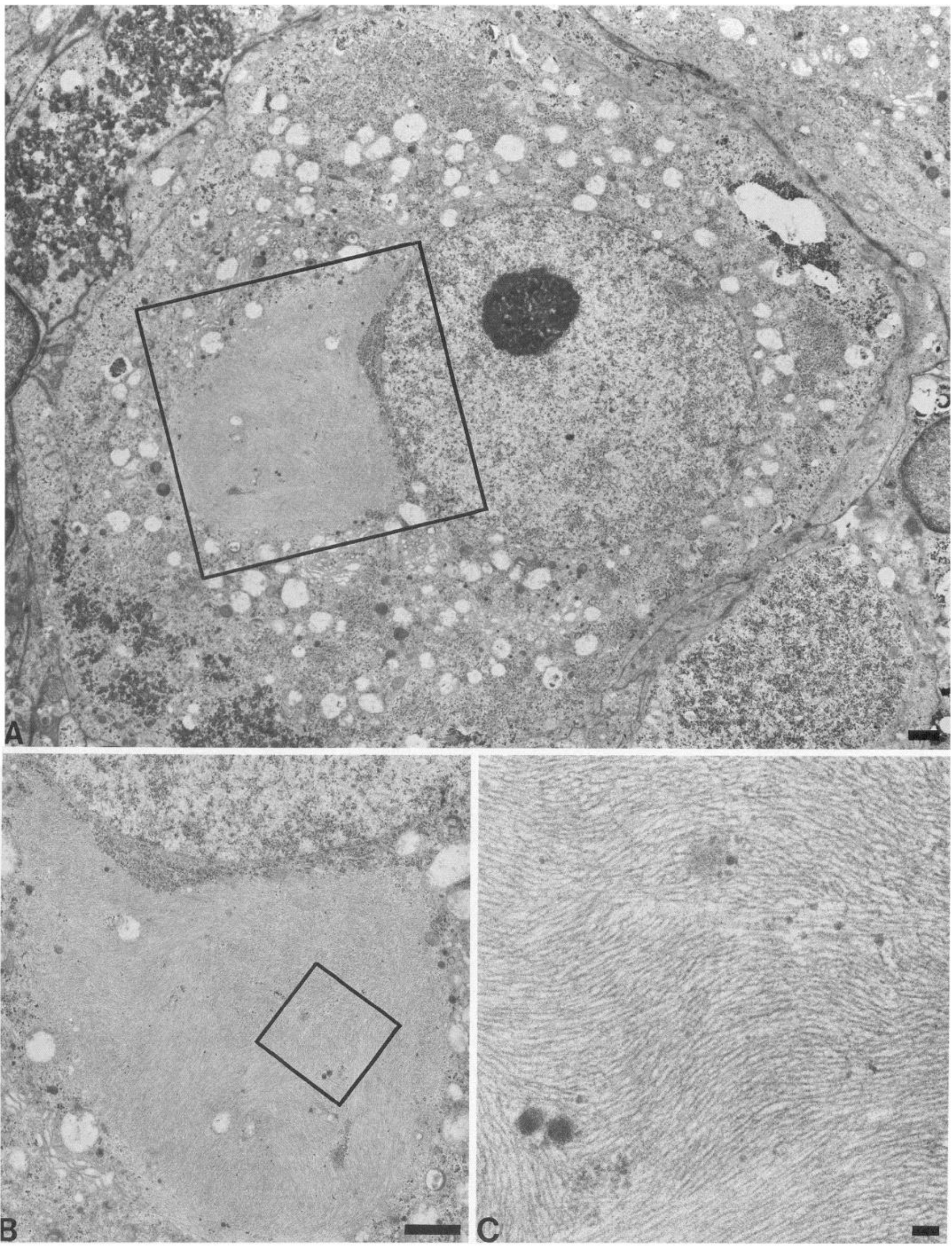




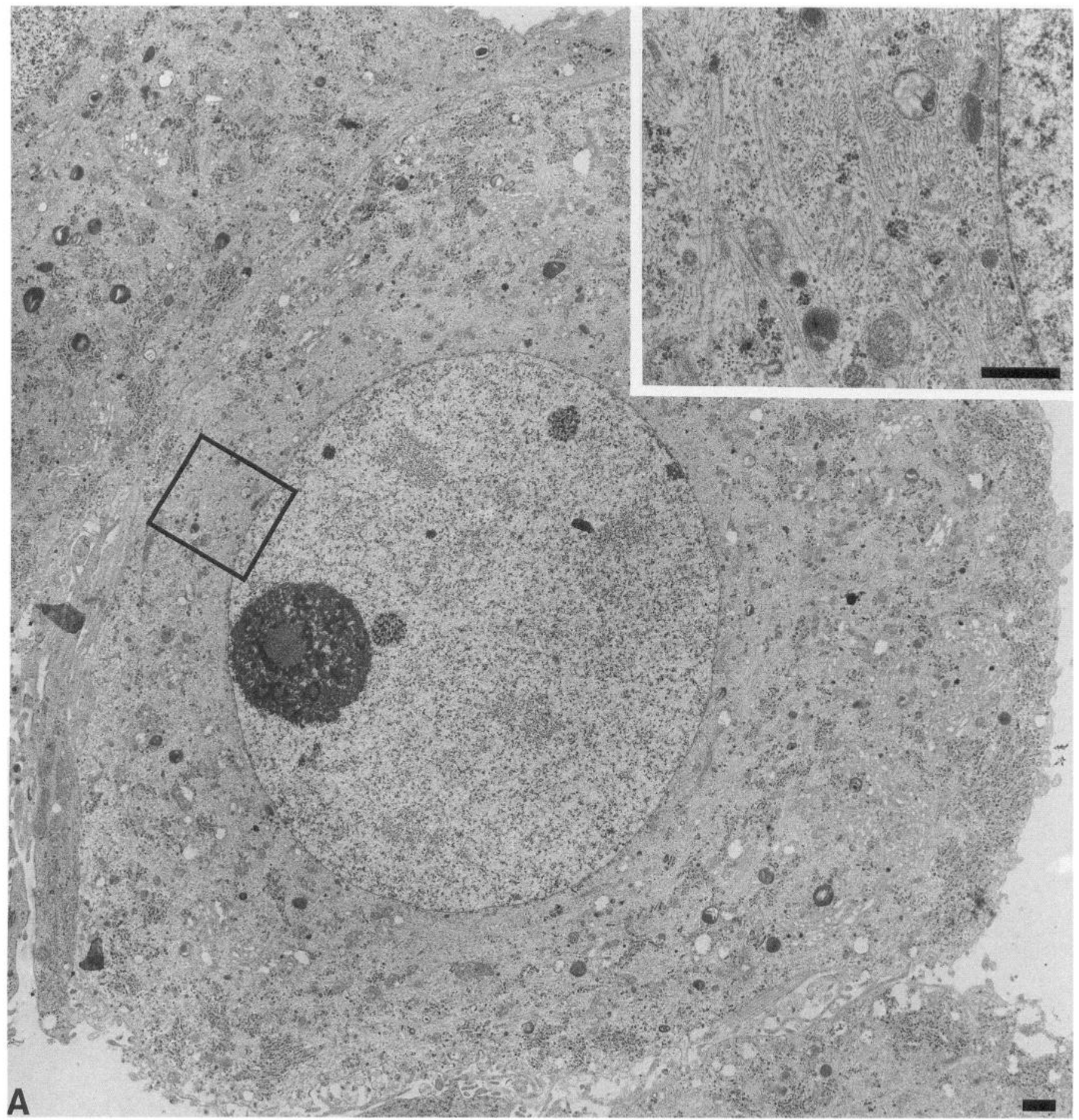

Figure 5. Electron micrograph of perikaryal region of cultured DRG neuron $7 \mathrm{~d}$ after $\mathrm{Al}$ was removed from the medium. $A$, Perinuclear region without a distinct filamentous mass. Inset, Cytoplasmic elements and microtubules are noted with NFs (from boxed region in $A$ ). Scale bars: $A$, 1 $\mu \mathrm{m} ;$ inset, $0.5 \mu \mathrm{m}$.

exposure. After $1 \mathrm{~d}$, an increased number of NFs was detected in a portion of the perikaryon (Fig. $2 A, B$ ). NFs were scattered among normal organelles and other cytoplasmic elements (Fig. $2 C$ ). After $3 \mathrm{~d}$, NFs accumulated in the perinuclear region (Fig. $3 A$ ) with almost complete exclusion of other elements (Fig. $3 B$ ). Higher magnification confirmed the nearly exclusive presence of NFs in the region (Fig. 3C). After $7 \mathrm{~d}$, the neurofilamentous mass was similar in appearance to the $3 \mathrm{~d}$ exposure (Fig. $4 A-$ C). At both 3 and $7 \mathrm{~d}$, filaments in the masses were densely packed and had relatively scarce side-arms similar to NFs in the perikaryon of untreated neurons.

One week after removal of the aluminum from the medium, the cells showed evidence of recovery. There was dispersal of the neurofilamentous accumulations from the perinuclear region 


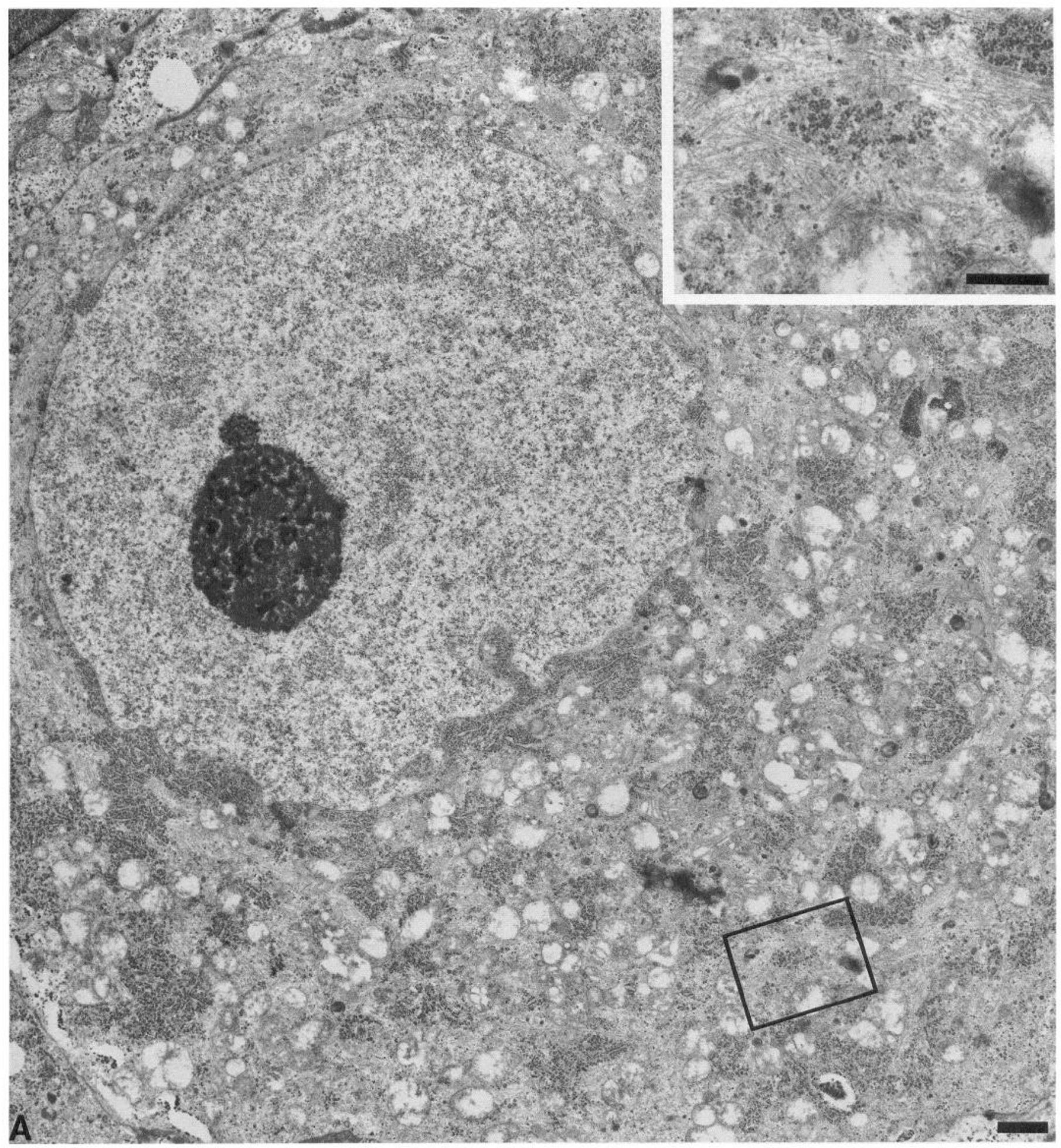

Figure 6. Electron micrograph of perikaryal region of untreated cultured DRG neuron at the same day in vitro as treated cultures (inset is from boxed region in $A$ ). Scale bars: $A, 1 \mu \mathrm{m}$; inset, $0.5 \mu \mathrm{m}$.

(Fig. $5 A$ ), and normal cellular organelles reappeared in this region (Fig. 5, inset). Control cultures showed a normal number and distribution of NFs in the perikaryon (Fig. 6).

\section{mRNA analysis}

mRNA levels for all three NF proteins were markedly decreased after only $1 \mathrm{~d}$ of exposure (Fig. 7) and remained very low for the entire $7 \mathrm{~d}$ exposure. However, levels of class II $\beta$-tubulin mRNA showed only a moderate decrease over the course of the experiment. Control cultures showed levels of NF mRNAs that were intermediate between the low levels in DRG of newborn rats and the high levels found in adults. These observations are consistent with our previous evaluation of age-related changes in cultured ganglia (Gilbert, 1989). One week after removal of 


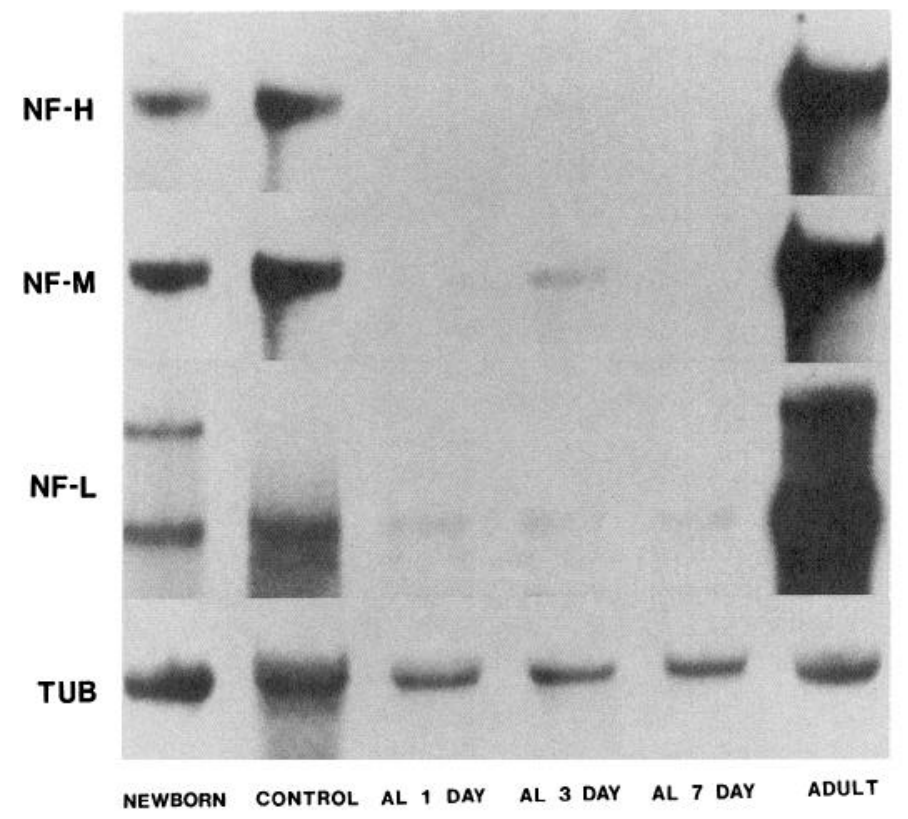

Figure 7. Comparison of changes in NF $(N F-H, N F-M, N F-L)$ and class II $\beta$-tubulin $(T U B)$ mRNA levels with duration of exposure to $\mathrm{Al}$. $N E W B O R N$, mRNA from newborn rats; $A D U L T$, mRNA from 10week-old rats; $C O N T R O L$, untreated cultures of the same age as treated cultures.

the aluminum from the medium, levels of NF and tubulin mRNA levels were increased in comparison to cultures harvested without a recovery period (Fig. 8).

\section{Discussion}

This study demonstrates that exposure of neurons in DRG explant cultures to aluminum lactate causes perikaryal accumulations of NFs in the perikaryon and that this change is accompanied by a marked reduction in levels of NF mRNA. The changes are similar to those described following $\mathrm{Al}$ exposure of DRG explants from fetal rabbits (Seil et al., 1969), with in vivo exposure of rabbits (Wisniewski et al., 1967; Troncoso et al., 1982), and following $\mathrm{Al}$ exposure of a neuroblastoma cell line (Miller and Levine, 1974; Shea et al., 1989). This observation has important implications. It is now possible to use cultured rat DRG explants to explore the molecular pathogenesis of aluminum-induced accumulation of NFs in aluminum toxicity. In addition, the fact that cultured rat DRG neurons develop accumulations of NF after exposure to aluminum salts suggests that neither the differences in vulnerability among neuronal populations nor those among species are absolute.

There are several possible explanations for this apparent species related difference in susceptibility to aluminum exposure in vivo. The failure to induce NF changes with aluminum may be related to interspecies differences in clearance or access of the toxin to neurons. In contrast, permeability barriers are absent in the culture system. Cell viability depends on adequate diffusion of nutrient medium, thereby assuring that all cells are exposed to toxin. Furthermore, differences in the concentration or stability of the cellular pool of NFs during development may also be important in determining the susceptibility to aluminum. The neurite cytoskeleton in the cultured DRG is similar to that found in immature animals (Gilbert, 1989), such as the young rabbits used in aluminum studies.

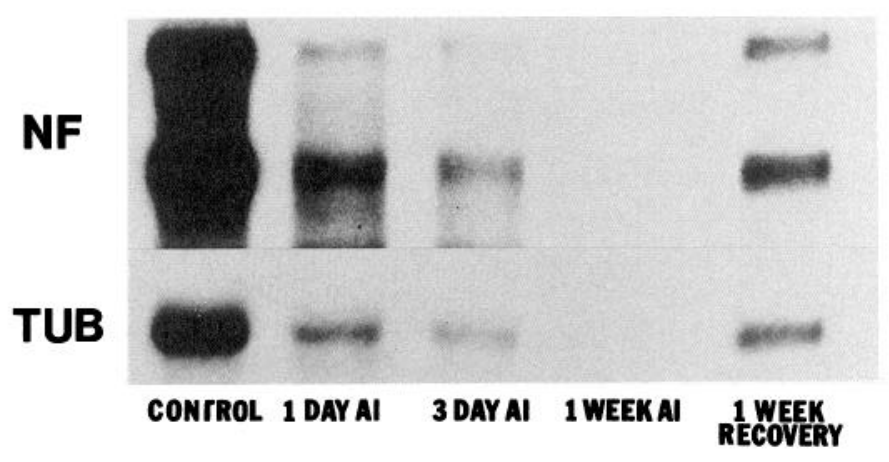

Figure 8. Changes in neurofilament (NF-L) and class II $\beta$-tubulin (TUB) mRNA levels after removal of $\mathrm{Al}$ from the nutrient medium. $\mathrm{CON}$ TROL, Untreated cultures of the same age as treated cultures.

Measurement of levels of NF mRNA revealed a marked decrease for all three NF proteins even after only $24 \mathrm{hr}$ of exposure to aluminum. This change in mRNA levels is associated with an increase in the percentage of neurons with perikaryal argyrophilic masses and segregation of NFs in the perinuclear region by ultrastructural evaluation. These morphologic and mRNA changes persisted for the entire $7 \mathrm{~d}$ exposure to aluminum. Levels of tubulin mRNA were moderately lowered, indicating that the consequences of $\mathrm{Al}$ exposure, although predominantly affecting the NFs, also cause a reversible decrease in class II $\beta$-tubulin gene expression. There is evidence that aluminum salts stabilize microtubules and may alter tubulin subunit equilibrium (Macdonald et al., 1987), which could account for the changes in tubulin mRNA levels. During recovery, manifested by a gradual dispersal of the neurofilamentous accumulation in the perikaryon, levels of NF mRNA were increased. The basis for this regulation of NF mRNA is not known, but our data suggest that the control of NF gene expression may be related to changes in the concentration of NFs in the perikaryon or to a direct effect of $\mathrm{Al}$ on mRNA production or stability.

This tissue culture model provides a useful system to study the consequences of NF abnormalities because it allows careful control of the experimental conditions, including the concentration of the neurotoxic agent, as well as permitting ongoing observation of morphologic changes and toxicity. It also provides an isolated group of uniformly exposed neuronal cells that enable in-depth molecular investigation of the consequences of aluminum exposure and control of NF gene expression.

\section{References}

Bizzi A, Gambetti P (1986) Phosphorylation of neurofilaments is altered by aluminum intoxication. Acta Neuropathol (Berl) 71:154 158.

Bizzi A, Crane RC, Autilio-Gambetti L, Gambetti P (1984) Aluminum effect on slow axonal transport: a novel impairment of neurofilament transport. J Neurosci 4:722-731.

Cole GM, Wu K, Timiras PS (1985) A culture model for age-related human neurofibrillary pathology. Int J Dev Neurosci 3:23-32.

Embree LJ, Hamberger A, Sjostrand J (1967) Quantitative cytochemical studies and histochemistry in experimental neurofibrillary degeneration. J Neuropathol Exp Neurol 26:427-436.

Exss RE, Summer GK (1973) Basic proteins in neurons containing fibrillary deposits. Brain Res 49:151-164.

Gilbert MR, Harding BL, Hoffman PN, Griffin JW (1989) Cytoskeletal changes during growth and regeneration of cultured dorsal root ganglia. Soc Neurosci Abstr 15:350.8.

Macdonald TL, Martin RB (1988) Aluminum ion in biological systems. Trends Biochem Sci 13:15-19. 
Macdonald TL, Humphreys WG, Martin RB (1987) Promotion of tubulin assembly by aluminum ion in vitro. Science 236:183-186.

Miller CA, Levine EM (1974) Effects of aluminum salts on cultured neuroblastoma cells. J Neurochem 22:751-758.

Muma NA, Troncoso JC, Hoffman PN, Koo EH, Price DL (1988) Aluminum neurotoxicity: altered expression of cytoskeletal genes. Mol Brain Res 3:115-122.

Seil FJ, Lampert PW, Klatzo I (1969) Neurofibrillary spheroids induced by aluminum phosphate in dorsal root ganglia neurons. J Neuropathol Exp Neurol 28:74-85.

Selkoe DJ, Liem RK, Yen S-H, Shelanski ML (1979) Biochemical and immunological characterization of neurofilaments in experimental neurofibrillary degeneration induced by aluminum. Brain Res 163: 235-252.

Shea TB, Clarke JF, Wheelock TR, Paskevich PA, Nixon RA (1989) Aluminum salts induce the accumulation of neurofilaments in perikarya of NB2a/d1 neuroblastoma. Brain Res 492:53-64.

Terry RD, Pena C (1965) Experimental production of neurofibrillary degeneration. 2. Electron microscopy, phosphatase histochemistry and electron probe analysis. J Neuropathol Exp Neurol 24:200-210.
Troncoso JC, Price DL, Griffin JW, Parhad IM (1982) Neurofibrillary axonal pathology in aluminum intoxication. Ann Neurol 12:278-283.

Troncoso JC, Hoffman PN, Griffin JW, Hess-Kozlow KM, Price DL (1985) Aluminum intoxication: a disorder of neurofilament transport in motor neurons. Brain Res 342:172-175.

Troncoso JC, Sternberger NH, Sternberger LA, Hoffman PN, Price DL (1986) Immunocytochemical studies of neurofilament antigens in the neurofibrillary pathology induced by aluminum. Brain Res 364 295-300.

Troncoso JC, March JI, Häner M, Aebi U (1990) Effect of aluminum and other multivalent cations on neurofilaments in vitro: an electron microscopic study. J Struct Biol 103:2-12.

Wisniewski HM, Narkiewicz O, Wisniewski K (1967) Topography and dynamics of neurofibrillary degeneration in aluminum encephalopathy. Acta Neuropathol (Berl) 9:127-133.

Wood P (1976) Separation of functional Schwann cells and neurons from normal peripheral nerve tissue. Brain Res 115:361-375. 